\title{
Discursos práticos sobre ocorrências, processos decisórios e decorrências de Conferências Municipais de Saúde
}

\author{
Alcides Silva de Miranda ${ }^{(a)}$ \\ Ana Ester Maria Melo Moreira ${ }^{(b)}$ \\ Caio Garcia Correia Sá Cavalcantic(c) \\ Fernanda Machado Bezerra(d) \\ Jéssica da Costa de Oliveira(e) \\ Regiane Rezende ${ }^{(f)}$
}

Miranda AS, Moreira AEMM, Cavalcanti CGCS, Bezerra FM, Oliveira JC, Rezende R. Practical discourses about events, decisions processes and effects of Health municipal conferences in Brazil. Interface (Botucatu). 2016; 20(58):559-71.

What can be elicited from the discourse analysis of Municipal Health Conferences attendees regarding these meetings, its decision-making processes and results? This is a multiple case study of events that took place in six towns in the State of Ceará (Northeast of Brazil) in 2007, based on documental review, interviews and focus groups, with a hermeneutics and dialectic analysis. Throughout these meetings, there are evidences of the voice and the advocacy of groups with specific requests, under a landscape of competitive dialogue and the search of political mediations pursuing symbolical effectiveness. From the decision-making process point of view, the more relevant elements are the statements concerning the negligence of municipal governments on incorporating these resolutions on their political agenda and its corresponding institutional implantation strategies, as well as the absence of supervision by the Municipal Health Councils.

Keywords: Health Conferences. Health Councils. Brazilian National Health System. Citizen participation.
Que significados podem ser evidenciados em discursos de participantes de Conferências Municipais de Saúde acerca de tais eventos, seus processos decisórios e decorrências? Para analisar tais discursos práticos, referidos a eventos ocorridos em seis municípios do Ceará em 2007, realizou-se estudo de casos múltiplos, a partir de análise documental, entrevistas e grupos focais, com análise hermenêutica e dialética. Sobre as ocorrências dos eventos, evidenciam-se as oportunidades de expressão e mobilização de alguns grupos de interesses por demandas específicas, em cenários de interlocução competitiva e busca de mediações políticas visando eficácia simbólica eventual. Dentre as decorrências a partir das decisões deliberadas, destacam-se discursos sobre a negligência de governos municipais na incorporação dessas demandas em suas agendas políticas e na implantação de estratégias institucionais correspondentes. Como, também, a ausência de monitoramento a fim por parte dos respectivos Conselhos Municipais de Saúde.

Palavras-chave: Conferências de Saúde. Conselhos de Saúde. Sistema Único de Saúde. Participação cidadã. (a) Departamento de Apoio e Orientação Profissional, Universidade Federal do Rio Grande do Sul (UFRGS). Anexo I da Saúde, UFRGS. Rua Ramiro Barcelos, 277, sala 155. Porto Alegre, RS, Brasil. 90035-007. alcides.miranda@ufrgs.br

(b) Departamento e

Curso de Psicologia Universidade Federal do Piauí. Parnaíba, PI, Brasil. estermelouniversidade@ gmail.com

(c) Direção de Educação Profissional em Saúde, Escola de Saúde Pública do Ceará. Fortaleza, CE, Brasil.caio.cavalcanti@ esp.ce.gov.br

(d,e) Departamento de

Saúde Comunitária, Faculdade de

Medicina, Universidade Federal do Ceará. Fortaleza, CE, Brasil. fernandamb1901@ gmail.com;

jessica.kinha.oliveira@ hotmail.com

(f) Unidade Técnica de Determinantes Sociais da Saúde, Riscos para a

Saúde, DCNT e Saúde Mental, OPAS/OMS Brasília, DF, Brasil. rezenderegiane@ yahoo.com.br 


\section{Introdução}

Em estudos e publicações recentes, têm sido cada vez mais proeminentes os enfoques que tratam da participação e controle de representações da sociedade civil e grupos de interesses sobre a formulação, a decisão e a implementação de políticas e estratégias governamentais de Saúde.

Muitos autores têm discutido sobre as influências e decorrências da institucionalização de espaços e processos de gestão participativa e de decisões para o controle público/social sobre as políticas governamentais de saúde. Tal discussão se insere num contexto mais abrangente, que trata de questões relacionadas com as reformas contemporâneas de Estado e os modos de participação social, governabilidade e governança.

Considerados os estudos e publicações afins, observa-se ênfase em assuntos que versam sobre:

- análises de normas e marcos regulatórios para a participação e controle público/social;

- relatos de experiências de gestão institucional participativa a partir de instâncias e processos decisórios correlatos;

- descrições sobre grupos e dinâmicas de representação de interesses no setor governamental de Saúde;

- análises sobre tipos de vocalização e mobilização por demandas de grupos específicos;

- descrições sobre os modos e meios de controle social e de fiscalização sobre a proatividade e as ações governamentais afins.

Tendo em vista as publicações internacionais mais relevantes sobre essa temática, predominam enfoques sobre as modalidades e impactos de participação referida como "comunitária", além de processos de responsabilização e controle da sociedade sobre sistemas e serviços de saúde de âmbito local ${ }^{1-3}$.

Alguns autores já realizaram revisões sistemáticas de estudos sobre a participação social em sistemas e políticas governamentais de saúde. Por exemplo, Evans et al. ${ }^{4}$ revisaram cinco mil e quatrocentas publicações sobre o impacto de abordagens participativas em unidades de saúde do Reino Unido, tendo considerado somente oito estudos mais relevantes, a partir de critérios preestabelecidos para a avaliação metodológica de qualidade. O que os levou a concluir que existe pouca evidência de estudos empíricos acerca do impacto da participação e controle da sociedade sobre as políticas governamentais de saúde naquele país.

No Brasil, as instâncias de controle social já estão institucionalizadas há quase duas décadas. Desde então, muitos estudos buscam evidenciar a importância e relevância de tais instâncias no processo de intermediação de interesses políticos, técnicos e administrativos para as representações da sociedade civil $^{5-8}$.

Têm sido abundantes as publicações sobre a participação e controle de representações da sociedade civil, notadamente a partir de Conselhos de Saúde, em políticas, sistemas, serviços e ações governamentais de Saúde. Nos estudos brasileiros sobre a participação popular e as instâncias de controle social em Saúde, predominam abordagens e análises pautadas em princípios e atributos de representação social e caráter de representatividade sob a égide democrática. Embora existam análises teóricas mais abrangentes ${ }^{9,10}$, predominam publicações sobre relatos de casos e análises sobre a atuação de Conselhos de Saúde municipais, estaduais e o nacional ${ }^{6,10-12}$.

Nota-se que têm sido escassas as publicações sobre estudos brasileiros que analisam a proatividade governamental em função das deliberações oriundas de instâncias de controle social no setor de Saúde. Isso ocorre em termos da observância, da incorporação, da implantação e da implementação de políticas e estratégias governamentais coerentes e correspondentes com as diretrizes estabelecidas nas deliberações de Conferências e Conselhos de Saúde.

Apesar da abundância de estudos e publicações sobre os Conselhos de Saúde, ainda são escassos os estudos e publicações que tratam especificamente sobre Conferências de Saúde ${ }^{5,13,14}$, instâncias formais de Controle Social de ocorrência periódica cujos propósitos normativos consistem em realizar avaliações sobre situações de saúde, além de formular, propor e deliberar diretrizes para as políticas públicas do setor. 
Nesse recorte particular, sobre Conferências de Saúde, pode ser enfatizado um estudo feito no estado de Mato Grosso, em que se analisaram diretrizes e demandas deliberadas em municípios ${ }^{14}$. No exemplo referido, utilizou-se estudo de casos múltiplos, com seleção de municípios por região e porte populacional, tendo sido realizadas entrevistas com participantes dos eventos e análise documental correspondente. A partir da análise do estudo, os autores evidenciam que as Conferências Municipais eram consideradas importantes pelos participantes, notadamente por favorecerem a explicitação das demandas locais. Entretanto, constatam o predomínio de uma percepção sobre a restrita influência de tais conferências na definição de prioridades para as respectivas políticas governamentais.

Considerada a exiguidade de estudos empíricos específicos sobre Conferências de Saúde no Brasil, observam-se lacunas em termos de substratos e subsídios para análises afins.

No estudo ora apresentado, o substrato primordial para a análise de ocorrências e decorrências de Conferências Municipais de Saúde são discursos práticos proferidos por alguns participantes selecionados. Segundo Jürgen Habemas, discursos práticos são: proferimentos de caráter mais regulativo, avaliações sobre prescrições, tensões normativas e fatos constatados em termos da aplicabilidade e eficácia de determinadas normas (idealizações, situações ideais, regras, diretrizes, procedimentos correlatos, etc.) no mundo real, nas relações cotidianas ${ }^{15}$. Tais discursos práticos podem evidenciar contradições e/ou convergências com validações consensuais e modos de legitimação para determinadas normas problematizadas ${ }^{16}$.

Convém realçar que, muitas vezes, a pretensão discursiva de aplicabilidade e eficácia para determinadas normas também pode ser evidenciada por interações mais dramatúrgicas, sem maiores decorrências efetivas. Nesses casos, os discursos práticos limitam-se aos "jogos de cena", notadamente em processos decisórios, em que prepondera o exercício de competências dramatúrgicas em busca de eficácia simbólica circunstancial. No caso dessa abordagem, a ideia de eficácia simbólica serve para caracterizar interações mais dramatúrgicas, limitadas aos processos decisórios eventuais, contudo, sem maiores decorrências práticas em temos de aplicabilidade e efetividade política.

Nos termos específicos desse estudo, as referências e tensões normativas estão estabelecidas pelo que se define ou se prescreve idealmente para a realização de Conferências Municipais de Saúde; e, também, pelo que se prescreve a partir das decisões deliberadas nessas instâncias, estabelecidas como diretrizes estratégicas para as políticas governamentais de saúde.

Em perspectiva dialética, os discursos práticos de representantes de grupos de interesses (singulares e plurais, particulares e gerais) implicados diretamente em processos decisórios e deliberações formais de tal natureza e caráter podem denotar contradições, tensionamentos, mediações e arranjos sintéticos possíveis; podem auxiliar no entendimento acerca da constituição de uma cultura de participação formal e de representação de interesses no campo da Saúde. Eis o foco e propósito dessa publicação, com a pretensão de que possa ter alguma utilidade para um melhor conhecimento acerca das Conferências de Saúde no Brasil, seu aprimoramento organizativo e maior efetividade.

\section{Aspectos metodológicos}

Realizou-se um estudo de casos múltiplos com níveis de análise imbricados ${ }^{17}$, de enfoque mais qualitativo e com análise hermenêutica e dialética, a partir de proferimentos discursivos provenientes de análise documental, entrevistas e grupo focal.

Como requisito primordial para a definição da amostra intencional, buscaram-se municípios localizados nas três Macrorregiões de Saúde do estado do Ceará e com a ocorrência de Conferências Municipais de Saúde no ano de 2007. A amostragem intencional visou uma diversidade de condições e situações a partir de alguns indicadores demográficos, socioeconômicos e epidemiológicos. A seleção intencional de municípios não se amparou em premissa ou hipótese de que quaisquer das condições consideradas implicassem em interferência ou influência específicas sobre os casos-eventos estudados, mas, tão somente, na intenção de buscar a diversificação de contextos onde os eventos ocorreram. Assim, definiram-se seis casos-eventos como unidades de análise, correspondentes às Conferências ocorridas em 2007 em três Macrorregiões de Saúde: 
- Macrorregião do Cariri: Brejo Santo e Baixio;

- Macrorregião de Fortaleza: Fortaleza e Tauá;

- Macrorregião de Sobral: Barroquinha e Sobral.

Para o processamento e análise documental, consideraram-se os relatórios finais das seis Conferências Municipais de Saúde listadas e Relatórios Anuais de Gestão em Saúde dos respectivos municípios (período 2004-2009).

Para a consecução de entrevistas com informantes-chave, realizou-se, inicialmente, o treinamento dos entrevistadores. Em seguida, ocorreram as primeiras visitas aos municípios selecionados, com identificação e seleção inicial de informantes e indicação dos demais (técnica "bola de neve"). Como critério de inclusão para os informantes, definiu-se a participação efetiva deles nos eventos-casos. Além disso, adotou-se o critério de diversidade dos segmentos de representação nas Conferências de Saúde: usuários, profissionais, prestadores de serviços e dirigentes governamentais.

Para a definição do limite de entrevistas individuais, levaram-se em conta os critérios de exaustividade e recorrência dos conteúdos discursivos analisados. No total, foram realizadas 32 entrevistas com distintos informantes dos municípios selecionados.

Após a análise inicial de entrevistas, constatou-se a necessidade de maior ênfase em enfoques discursivos de participantes não vinculados a Conselhos Municipais de Saúde (conselheiros) e governos municipais (dirigentes). Para a obtenção de discursos específicos desse perfil de participantes, em perspectiva mais dialógica, optou-se pela técnica de grupo focal, realizando-se duas sessões de grupo focal, com a participação de onze convidados oriundos dos municípios selecionados (exceto Brejo Santo).

Tanto as entrevistas individuais como as sessões de grupos focais foram gravadas e transcritas literalmente. O material escrito, constituído pela análise documental e a transcrição das gravações, foi processado e analisado com o auxílio dos programas Logos, para categorização, e Xmind, para montagem de redes de significados.

Para a categorização temática do material transcrito, adaptou-se uma técnica auxiliar referida no método de Análise de Conteúdo, do tipo "categorial e temático"18.

Em seguida, procedeu-se com a análise intertextual dos discursos práticos, com a formulação de categorias de síntese a partir de analogias e/ou contradições identificadas.

Para o tratamento de análise hermenêutica e dialética, em perspectiva de sentido e síntese, realizouse o percurso de logística de integração analítica proposto por Testa ${ }^{19}$ :

- análise extensiva com descrição de fatos;

- análise intensiva com explicação de significados (categorização);

- análise hermenêutica intertextual com compreensão de sentido; e

- análise dialética de síntese contextual.

O projeto do estudo foi submetido e aprovado no Comitê de Ética da Pesquisa da Universidade Federal do Ceará. No decorrer do estudo, observaram-se e cumpriram-se os requisitos de procedimentos éticos da, então vigente, Resolução 196/96 do Conselho Nacional de Saúde.

\section{Resultados}

Em se tratando de material extenso, a descrição sumária de resultados se atém a aspectos descritivos e temas considerados mais relevantes pelos pesquisadores. De início, em termos de enfoque extensivo (descrições) e intensivo (explicações), são descritos aspectos da análise documental e proferimentos discursivos mais significativos, sintagmas provenientes da análise de entrevistas e grupo focal. Em seguida, em termos de enfoque intertextual hermenêutico (interpretações) e contextual dialético (contradições e síntese), apresenta-se uma figura com a esquematização de categorias e circuitos proeminentes. 


\section{Descrições evidenciadas em discursos formais, a partir da análise documental}

Em consonância com o contexto normativo do Sistema Único de Saúde, as demandas e diretrizes identificadas na análise documental podem ser classificadas a partir das dimensões de promoção, proteção e recuperação, ou seja, assistência e reabilitação da saúde.

Denota-se, na análise sobre os registros documentados acerca das deliberações das Conferências Municipais de Saúde - notadamente, naquelas realizadas nos municípios do interior -, pouca ênfase na deliberação de diretrizes afins com os componentes de promoção e proteção da saúde, assim como quanto a determinados campos de atuação, tais como: Vigilância Sanitária, Vigilância Epidemiológica, Vigilância Nutricional, Orientação Alimentar, Saúde do Trabalhador e Proteção do Meio Ambiente.

Evidencia-se maior ênfase nas deliberações atinentes ao componente de recuperação da área da Saúde, particularmente em seu aspecto assistencial, referido: aos campos de atuação de estratégias e serviços hospitalares e de Atenção Básica (estratégia programática de Saúde da Família), acessibilidade a insumos, sobretudo, farmacêuticos, e demandas de profissionais de saúde.

Quanto ao aspecto de reabilitação em saúde, constatou-se uma exiguidade de deliberações associadas a: políticas, estratégias institucionais, programas, serviços e ações dessa natureza.

Particularmente dois temas referentes aos direitos e princípios previstos na legislação do SUS são mais enfatizados: o tema da preservação da autonomia das pessoas na defesa de sua integridade física e moral, e o tema da "igualdade da assistência à saúde, sem preconceitos ou privilégios de qualquer espécie", consideradas as seguintes características distintivas e proeminentes: demandas referentes ao campo de Saúde Mental na Conferência da capital e demandas de populações rurais nas Conferências dos municípios interioranos.

As questões relativas à participação popular são recorrentes, com ênfase nas demandas de formação e capacitação dos representantes de usuários que atuam nos Conselhos Municipais de Saúde. Nesse tema particular, cobra-se uma maior participação e implicação das instituições públicas de ensino.

No contexto extrínseco aos municípios estudados, estão explicitadas demandas acerca de uma melhor integração e complementaridade entre as ações governamentais oriundas das três esferas de governo. O governo federal, muitas vezes, é caracterizado como plenipotenciário e detentor da maior capacidade de investimento e sustentação financeira; ao mesmo tempo, é responsabilizado pela maior parte das dificuldades associadas à escassez de recursos financeiros.

No que se refere ao contexto intrínseco dos municípios, existem frequentes demandas de investimentos estruturais para os sistemas e serviços de saúde. Denota-se que algumas dessas demandas extrapolam o caráter meramente setorial da Saúde e estão orientadas para investimentos intersetoriais, como: habitação, lazer, escolas, creches, etc. O que coaduna com a perspectiva de políticas e estratégias institucionais orientadas para a Promoção de Saúde. Ainda assim, predominam as reivindicações para investimentos estruturais, tais como: construção e reformas de serviços de saúde, em especial, de Atenção Básica e Saúde Mental, aquisição e manutenção de equipamentos e melhorias nos transportes.

Acerca do componente de trabalho profissional, são mais recorrentes as demandas para a contratação de profissionais médicos. Também existem demandas para a contratação de outros profissionais de nível Superior, sobretudo para os serviços da Estratégia de Saúde da Família, inclusive, de profissionais especializados em práticas integrativas e complementares. Há ênfase em deliberações acerca da modalidade de contratação pela via de concursos públicos, e críticas acerca das modalidades de contratação por terceirização e por fundações ou organizações sociais, reiteradas, especialmente, nos municípios de maior porte populacional.

Há muitas deliberações para a ampliação dos horários de atendimento nos serviços de saúde, com a inclusão do horário noturno nos municípios de maior porte populacional. Observa-se, ainda, que existem queixas e cobranças por um maior controle do cumprimento de carga horária e permanência de profissionais nos serviços de saúde, notadamente nos serviços de Pronto-Atendimento de Urgência e Emergência. 
Também são recorrentes as demandas para o incremento de iniciativas de educação permanente e outras modalidades de formação e capacitação de profissionais na própria rede de serviços de saúde.

Estão registradas muitas demandas específicas de trabalhadores da área, com destaque para as solicitações de aumento salarial e regulamentação de Planos de Cargos, Carreiras e Salários.

De modo geral, observa-se que os registros das deliberações sobre demandas e asserções propositivas (diretrizes), provenientes de sínteses realizadas pelos relatores das Conferências Municipais, estão dispostos em conotações mais reivindicatórias, com delineamentos muito vagos e genéricos, sem melhor definição de metas específicas ou de dimensionamentos operativos (objetivação, quantificação, delimitação de prazos, etc.).

Em se tratando de documentos que deveriam servir, primordialmente, como substratos para a definição de diretrizes políticas e estratégicas para as políticas e ações governamentais de âmbito municipal, tal proeminência de conotação reivindicatória e caráter genérico requer processamento técnico e logístico posterior, o que não ocorreu em nenhum dos casos analisados. Nem agentes governamentais e nem outros agentes, representantes ou técnicos dos respectivos Conselhos Municipais de Saúde, relataram ou apresentaram registros documentais sobre iniciativas ou tratativas posteriores para o processamento técnico-político ou logístico a partir dos relatórios e outros registros das Conferências em questão. Infere-se que não ocorreu nenhum tipo de processamento desse tipo e que os registros permaneceram em seu estado original.

Alguns discursos práticos, evidenciados em relatos analisados a partir das entrevistas e Grupo Focal, dão conta de que tais relatórios e registros ficam arquivados e não são retomados como referenciamentos diretivos ou logísticos para pautas de discussões ou orientação de agendas de âmbito governamental e dos respectivos Conselhos Municipais de Saúde.

$\mathrm{Na}$ análise dos relatórios das Conferências Municipais realizadas em 2007, não foram encontrados registros ou informes sobre quaisquer ocorrências de avaliações ou balanços acerca da efetivação de políticas governamentais orientadas por diretrizes deliberadas nos eventos anteriores, realizados em 2003. Sequer existiam registros sobre discussões avaliativas e retrospectivas de grupos específicos ou de plenárias gerais sobre o alcance de metas ou resultados da efetivação de políticas governamentais correspondentes às diretrizes estabelecidas nas deliberações das Conferências anteriores.

\section{Explicações evidenciadas em entrevistas e grupo focal}

No aspecto da análise de discursos práticos oriundos das entrevistas e grupos focais, as principais categorias de análise identificadas reportam a conteúdos temáticos específicos, atinentes aos processos de organização das Conferências Municipais, sua realização e às decorrências posteriores.

No que tange ao processo de organização e mobilização para essas Conferências, observam-se queixas sobre a parca divulgação e comunicação insuficiente para o público em geral.

Reitera-se a importância da realização de pré-conferências - locais e temáticas - não somente pela necessidade de se contemplarem demandas mais específicas, mas pelo caráter pedagógico, de incremento comunicativo e de agregação participativa.

Existem, também, muitas alusões aos eventuais constrangimentos e tensões provocados pela partidarização política e aparelhamento político-partidário desses eventos e, notadamente, dos próprios Conselhos Municipais de Saúde. Essa temática é mais recorrente nos municípios de menor porte populacional, sendo que, em um deles, de porte médio, a temática tornou-se muito significativa em razão de um contexto de intensa polarização partidária.

De acordo com relatos, os momentos e cenários de encontros, interlocuções e celebrações são informais, e ocorrem nos entreatos das Conferências Municipais de Saúde. Tendem a ser muito valorizados em alguns proferimentos discursivos, interpretados como oportunidades de muitos perceberem que não estão isolados em suas lutas cotidianas por melhores condições de saúde, que "fazem parte de uma comunidade de 'construtores do SUS'" (Entrevista 8).

Há também proferimentos que conotam a participação e representação de alguns delegados nas Conferências como "elitizada", restrita àqueles iniciados no ativismo ou militância de movimentos sociais, afeitos a "discursos prontos, mais panfletários" (Participante 4, grupo focal). 
Alguns proferimentos denotam uma percepção de "repetitividade" nas pautas e temas tratados, caracterização também aludida a muitos representantes (delegados) e seus discursos proferidos por ocasião dos referidos eventos. Em outros termos, identifica-se uma repetição exaustiva de pautas, assuntos, representantes e discursos, o que, para alguns, dificultaria uma participação mais ampla de novos representantes e novas pautas.

Especificamente sobre as lembranças oriundas das Conferências Municipais de Saúde realizadas, há determinados proferimentos que denotam uma espécie de "lacuna de memória" acerca das principais deliberações. A maior parte dos entrevistados demonstra facilidade para lembrar de deliberações mais específicas, decorrentes de suas próprias demandas e contextualizadas localmente ou em perspectiva mais corporativa, no caso da representação de categorias profissionais ou de determinados grupos de interesses. Porém, revelam dificuldades para lembrar das decisões mais gerais, de caráter diretivo mais amplo. Para alguns entrevistados, a dificuldade em memorizar questões consideradas como substanciais nesses eventos deve-se ao período de tempo decorrido para a realização das mesmas.

Alguns dos entrevistados tentam explicar essa dificuldade de lembrança a partir da assertiva de que as deliberações "caem no esquecimento" porque o poder público, a gestão governamental, não busca efetivá-las posteriormente. Outros entendem que os próprios Conselhos e Conselheiros Municipais de Saúde não assumem a responsabilidade de tomar tais deliberações como pauta e agenda, não buscam o monitoramento cotidiano de sua efetivação por parte da gestão governamental. Para constatar ou refutar tal afirmação, seria necessária uma análise sobre as agendas e pautas decisórias dos respectivos Conselhos Municipais de Saúde, o que não se tornou possível em razão da inexistência ou incompletude de registros desse tipo na maior parte dos municípios estudados. No caso específico do Conselho Municipal de Saúde de Fortaleza, a análise das agendas e pautas decisórias registradas no período analisado evidencia que, em raríssimas ocasiões, houve discussões ou decisões acerca da implementação de deliberações provenientes das Conferências Municipais ocorridas em 2003 e 2007.

Quanto ao encaminhamento das diretrizes deliberadas nas Conferências aos entes governamentais e o seu concomitante monitoramento por parte das instâncias de Controle Social, muitos dos entrevistados e participantes do grupo focal exprimem sensações de desânimo, desmotivação e descrédito. Há uma recorrente constatação de que as deliberações não são tomadas como prioridades pelos governos municipais nem tampouco monitoradas ou avaliadas pelos respectivos Conselhos Municipais de Saúde.

Alguns dos entrevistados e participantes do grupo focal, na condição de conselheiros municipais de saúde (na ocasião ou em períodos anteriores), revelam que não ocorreram discussões ou avaliações nos conselhos acerca da inclusão de deliberações das Conferências Municipais em agendas governamentais, ou, mesmo, de monitoramento sobre a aplicabilidade e consecução de ações governamentais pertinentes e compatíveis com as referidas deliberações.

Da sua parte, alguns entrevistados e participantes do grupo focal, na condição de representantes do segmento governamental, afirmam que a inclusão de deliberações provenientes das conferências em agendas governamentais ocorre de modo "assistemático" (Participante 4, grupo focal) e "natural" (Entrevista 11). Enfatizam que a consecução de ações governamentais correspondentes são monitoradas pelos próprios governos municipais e apresentadas em relatórios de "prestação de contas" (relatórios de gestão e congêneres) para a apreciação e aprovação dos Conselhos Municipais de Saúde.

Evidencia-se concordância de interpretação, tanto nas entrevistas como no grupo focal, na constatação de que, nas próprias Conferências Municipais de Saúde, não houve avaliações prévias ou ocasionais e nem discussões específicas sobre o encaminhamento e consecução de ações governamentais correspondentes ou compatíveis com deliberações estabelecidas em conferências anteriores.

Assim como consta na análise documental, muitos proferimentos discursivos expressam necessidades e demandas para a "formação" e "capacitação" de conselheiros municipais de saúde, de modo a qualificar as suas intervenções de representação e de acompanhamento das deliberações ocorridas nas Conferências Municipais. 


\section{Categorias constituídas na análise intertextual hermenêutica e contextual dialética}

Para além dos aspectos descritivos e explicativos evidenciados em discursos formais e informais acerca dos casos-eventos analisados, a interpretação de sentido intertextual e contextual advém da configuração de uma rede de significados, com ênfase na interpretação de interações, associações e contradições discursivas expressas em categorias dialéticas. Não há, propriamente, relações de causa e efeito ou de associações hierarquizadas entre as categorias evidenciadas. Tampouco trata-se de configuração rizomática, pois busca-se apenas uma caracterização reticular de significados conexos a partir de uma matriz categorial em determinada intepretação de sentido.

Nessa configuração ilustrativa de temas evidenciados (Figura 1), as categorias dialéticas constituídas a partir dos proferimentos discursivos derivam de uma matriz dialética primordial: democracia participativa/representativa. Tal matriz está conectada com os cenários e processos decisórios em questão, as Conferências Municipais de Saúde, dinamizadas também por tensões dialéticas preponderantes entre o instituinte e o instituído. As diversas derivações estão referidas a aspectos tematizados acerca de determinações, ocorrências e decorrências que perfazem suturas dialéticas em um circuito hermenêutico com compreensão de sentido.

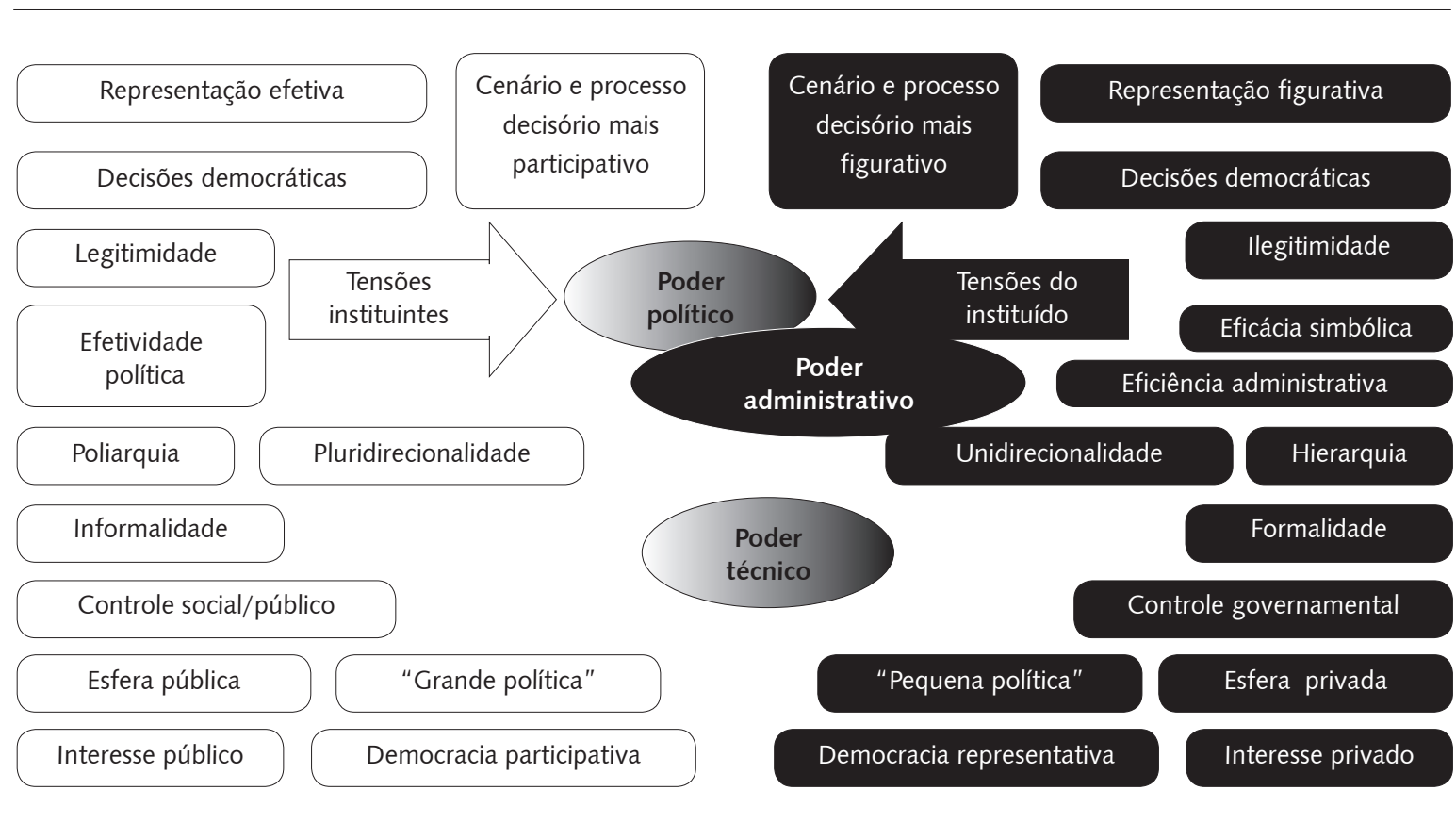

Figura 1. Configuração ilustrativa de categorias temáticas evidenciadas sob o enfoque intertextual hermenêutico e contextual dialético na análise sobre ocorrências, processos decisórios e decorrências de Conferências Municipais de Saúde no Ceará.

Em perspectiva instituinte, o circuito parte de tensões por melhor participação e inovações em termos de estratégias sociais e institucionais (administrativas, programáticas, etc.) para a direcionalidade política por meio de combinações entre razões, modos, meios e dispositivos de democracia direta (participativa) e indireta (representativa). Em tal combinação, há expectativa de preponderância da direcionalidade participativa e da condução governamental compatível e coerente.

Representações tidas como efetivas e legítimas visam salvaguardar ou promover o interesse público e a esfera pública (res pública) em conotação positiva para a política ("grande política", "política de Estado"). Admite-se que tais representações tendem: à informalidade, poliarquia (interesses diversos, 
ordenamentos plurais, arranjos múltiplos, margens de autonomia interdependentes), pluralidade de instâncias e de disputas direcionais, que requerem mediações políticas permanentes e consensos formais. Além disso, também requerem compromissos políticos de incorporação e efetivação de uma agenda direcional por parte dos governos, que são os responsáveis pela viabilização política, técnica e administrativa e pela condução, operacionalização e execução das deliberações provenientes das conferências.

Na perspectiva dos sistemas institucionalizados de ação, portanto, do polo instituído, o circuito também parte de tensões por mais participação direta e inovações estratégicas, em combinações de democracia participativa e representativa. Entretanto, em tal combinação, prevalece a expectativa da preponderância de atuações mais figurativas, ou seja, expressividades e interações dramatúrgicas, figurações expressivas das instâncias de Controle Social, com direcionalidade e condução governamental autônomas. Em outros termos, os governos proporcionam meios de participação e convivem com as instâncias de controle social (conferências com figuração dramatúrgica direcional, conselhos com figuração dramatúrgica fiscalizadora), mas operam com agendas próprias, autônomas e dissociadas das mesmas.

Representações tidas como figurativas ou ilegítimas visam os interesses privados, corporativos e de determinados grupos ou pessoas, em conotação negativa para a política ("pequena política", "mercado da política"). Admite-se que tais representações tenderiam a valorizar mais a disputa em expressões figurativas por demandas de grupos de interesses, enquanto as representações governamentais tenderiam a valorizar mais: as formalidades do burocratismo, as hierarquias de poder institucional (político, técnico, administrativo), as instâncias formais de governo e as disputas direcionais entre grupos de interesse que sustentam a governabilidade conjuntural. As deliberações das Conferências de Saúde servem mais como simulacros de participação, com alguma eficácia simbólica para demonstrar que os governos estão abertos à participação, mas suas deliberações não são incorporadas nas agendas governamentais e, portanto, não possuem quase nenhuma efetividade. Haveria disputas por poder efetivo (político, técnico e administrativo), mas, intrinsicamente, na institucionalidade governamental.

É claro que a definição esquemática e ilustrativa de circuitos, como interpretação de proferimentos discursivos e expectativas em questão, reduz a perspectiva dialética ao sentido dual, às vezes, maniqueísta (circuito virtuoso/vicioso). Daí, pois, convém reiterar que tais dinâmicas dialéticas não são assim redutíveis.

Nos circuitos hermenêuticos, busca-se somente evidenciar uma expectativa acerca de tipo ideal (democracia participativa como elemento combinatório de circuito virtuoso) e, notadamente, a predominância de uma constatação hegemônica: de democracia participativa como figuração de eficácia simbólica eventual, em circuito vicioso.

A constatação mais evidente de circuito hermenêutico preponderante refere-se a formas de democracia participativa com representação figurativa em conotação de que Conferências Municipais de Saúde analisadas possibilitaram diversas expressões e disputas por demandas predominantemente particulares em interações mais dramatúrgicas ${ }^{16}$, visando eficácia simbólica, aprovação pela maioria na forma de deliberações, ou eventual, restrita às ocorrências dos eventos. Entretanto, após o término dos referidos eventos, as diretrizes deliberadas mostraram-se sem efetividade política em termos de inclusão nas agendas governamentais dos respectivos municípios; e, menos ainda, em sua implementação e consecução sob a forma de políticas públicas governamentais.

\section{Discussão}

Em se tratando do contexto brasileiro no período contemporâneo de redemocratização da institucionalidade republicana, a política setorial de saúde pode ser definida como inovadora no que se refere às prerrogativas, razões e modos de ser e (atu)ações das instâncias de controle social em termos de conformação de tensões normativas, de configurações de estratégias institucionais e de inovações tecnológicas correlatas. 
A partir de indução normativa e num curto período de tempo, ocorreu ampla disseminação de instâncias e eventos de natureza plural e caráter mais participativo.

As Conferências de Saúde, como instâncias máximas do controle social em Saúde, possuem uma importância capital não somente em razão de sua atribuição legal de deliberar sobre diretrizes políticas e estratégicas para o Sistema Único de Saúde, mas em virtude de configurarem cenários de estímulo e renovação do ativismo no setor. Em dados momentos históricos, algumas conferências, em suas diversas etapas, tiveram uma função primordial de síntese e proatividade para mudanças institucionais significativas.

Ainda para além de suas atribuições legais e de tensão normativa, as conferências de Saúde promovem ritos de celebração, encontros, conexões e interações entre diversos atores sociais e grupos de interesse setoriais no setor de Saúde. São momentos muito ricos e estimulantes, quando se imbricam tramas e dramas de expressão e de vocalização de demandas, mobilizações de vontades entre os diversos e distintos grupos de interesse setoriais.

As Conferências Municipais de Saúde têm sido instâncias mais propícias para a atuação de ativistas e/ou militantes de causas e representantes de grupos de interesses com demandas mais específicas

As inovações institucionais que propiciam formas de democracia participativa demandam tensões e dinâmicas instituintes orientadas para a mudança, o crescimento e a busca de legitimação na institucionalidade pública; em contradição com tensões e movimentos instituídos, orientados para a conservação, o controle e a consolidação de determinados grupos de interesses que também buscam legitimação social. Nos cenários das Conferências Municipais, evidenciam-se disputas políticas por legitimidade social entre as tensões instituintes e do instituído.

Nos casos analisados, os cenários decisórios, como instâncias eventuais, ainda possuem uma conotação meramente simbólica e figurativa, o que ocorre, em certa medida, dada a assimetria de capitais políticos e a deficiência de competências de (inter)ação social da parte dos atores implicados. Mesmo assim, observa-se a emergência de uma tensão instituinte que: demanda mais autonomia política, busca enxertar modalidades de práticas participativas sob a hegemonia da institucionalidade representativa, busca o cultivo e exercício do diálogo e negociação, com vista a conformar modos de publicização e representação de interesses na esfera pública.

Por sua vez, a tensão instituída de democracia representativa tende a sobrepujar uma lógica de: reificação e subordinação às regras do mercado político, especialização e permanência, institucionalização de representações formais, intercâmbio entre representações de interesses particulares, cooperação ou adesão em troca de compensações ou premiações - às vezes, sob a forma de clientelismo.

Alguns estudos recentes $s^{4,10,11,14}$ apontam evidências acerca de certo esgotamento desse potencial de aproximação e implicação proativa entre modalidades de institucionalidade democrática representativas e participativas. De modo hipotético, não se trata do esgotamento das iniciativas de enxerto das modalidades de democratização participativa, mas da permanência e reiteração da cultura institucional de representação democrática nos moldes convencionais da democracia representativa, em que as novas representações e os novos representantes passam a atuar conforme as regras institucionais vigentes. Mesmo alguns representantes experientes de movimentos sociais passam a atuar de um modo típico da institucionalidade da democracia representativa, com uma especialização de papel e, muitas vezes, a perpetuação no cargo de representação.

Algumas questões devem ser apresentadas para a exploração, análise e argumentação acerca desse fenômeno de aparente esgotamento ou (re)colonização da esfera pública e de espaços decisórios tão importantes.

Quando instâncias formais de democracia participativa que visam estabelecer diretrizes (tensões normativas) para as políticas públicas e governamentais, mesmo que enxertadas perifericamente na institucionalidade democrática representativa, passam a adquirir caráter meramente figurativo, então, prepondera a racionalização instrumental e a indiferença estrutural ${ }^{1}$ - o que implica a substituição das prerrogativas decisionais de agentes públicos identificáveis (no caso, atores sociais proativos em interação dialógica) por operações seletivas incorporadas às rotinas de sistemas administrativos hierarquizados. Quem termina por definir o que é politicamente relevante, o que merece atenção e o 
que cai na área da indiferença não são os agentes públicos em instâncias de democracia participativa, mas os agentes governamentais em instâncias formais de governo e instâncias informais de mercado político, em intercâmbio de soma positiva restrito aos agentes e intermediadores das dinâmicas formais e informais de democracia representativa.

O que disfarça tal indiferença estrutural é, essencialmente, o discurso ideológico de cunho tecnoburocrático, que busca obstruir e interditar a abertura dos discursos práticos e impedir a tematização dos fundamentos do poder ${ }^{16}$. Algumas normas institucionais tendem à pseudolegitimação quando cumprem a dupla função de impedir que elas próprias e seus propósitos sejam tematizadas discursivamente. Em tal perspectiva, busca-se substituir as tensões normativas sociais por regras técnicas e administrativas. Assim, se as prerrogativas e os fundamentos do poder institucional não precisam ser tematizados, não é porque repousam sobre a normatividade legítima, mas porque a lógica das coisas passa a ser preponderante ${ }^{16}$.

As diretrizes deliberadas nas Conferências de Saúde não recebem quase nenhum processamento ou tratamento posterior de adequação em termos de reformulações como estratégias institucionais em busca de viabilização política, técnica e administrativa ou em termos de formulações de políticas institucionais viáveis. Permanecem como expressões de demandas genéricas, o que facilita a sua subordinação ou substituição por imposições técnicas e administrativas oriundas da normatividade governamental instituída.

O circuito hermenêutico vicioso da democracia representativa dependente do mercado político, pautada por interesses particulares, e da democracia participativa meramente figurativa, simulacro conveniente apenas em termos de eficácia simbólica eventual, gera desencanto e desânimo para os participantes de instâncias decisórias, como as conferências de Saúde, o que contribui para a deslegitimação dessas modalidades de participação.

Existe ainda uma contradição primordial entre perspectivas de gerar demandas políticas e gerir políticas governamentais no entorno das próprias instâncias de Controle Social. Contradições entre as prerrogativas das Conferências Municipais para gerar demandas, apontar diretrizes, proposições, requerer mais investimentos, mais autonomia, e as prerrogativas dos Conselhos Municipais de Saúde para gerir agendas deliberativas, fazer o controle e a fiscalização dos atos do poder executivo.

As demandas geradas a partir das deliberações das conferências tendem a encontrar pouca ressonância nos Conselhos Municipais Saúde, mais pautados pelas demandas governamentais.

Enfim, os casos analisados podem ser contextualizados na perspectiva de contradições, tensões e mediações substanciais para a democratização do Estado brasileiro, a consolidação da sociedade civil e a constituição de instâncias da esfera pública. Os discursos analisados, embora reiterem diversas contradições, também expressam expectativas de que as referidas Conferências Municipais possam se tornar algo mais do que cenários rituais de vocalizações simbólicas e eventuais de demandas fadadas ao confinamento em relatórios arquivados e esquecidos no limbo figurativo.

Em conclusão, denota-se que o presente estudo enfatiza interpretações acerca de fatos e fenômenos que podem ser analisados em muitas perspectivas teóricas e por meio de diversas metodologias. Assim sendo, muitos dos aspectos evidenciados como significativos nesse estudo requerem tratamento mais aprofundado e diversificado de análise. Requerem o balizamento com evidências e interpretações advindas de outros estudos similares ou de estudos com enfoques e métodos de análise distintos.

\section{Colaboradores}

O autor Alcides Silva de Miranda elaborou a versão inicial do artigo e participou de sua discussão, redação e da revisão do texto. Os demais autores participaram, igualmente, da discussão e da revisão do texto. 


\section{Referências}

1. Grindle MS, Thomas JW. Public choices and policy change: the political economy of reform in developing countries. London: The John Hopkins University Press; 1991.

2. Zakus JDL, Lysack CL. Revisiting community participation. Health Pol Plan. 1998; 13(1):1-12.

3. Derick W, Brinkerhoff DW. Accountability and health systems: toward conceptual clarity and policy relevance. Health Pol Plan. 2004; 19(6):371-9.

4. Evans D, Pilkington $P, M c E a c h r a n ~ M$. Rhetoric or reality? A systematic review of the impact of participatory approaches by UK public health units on health and social outcomes. J Public Health. 2010; 32(3):418-26.

5. Sayd JD, Vieira Júnior L, Velandia IC. Recursos Humanos nas Conferências Nacionais de Saúde. Physis. 1998; 8(2):165-95.

6. Guizard FL, Pinheiro R, Mattos RA, Santana AD, Matta G, Gomes MCPA. Participação da comunidade em espaços públicos de Saúde. Physis. 2004; 14(1):15-39.

7. Vazquez ML, Ferreira da Silva MRA, Gonzales ESC, Diniz AS, Pereira APC, Veras ICL, et al. Nível de informação da população e utilização dos mecanismos institucionais de participação social em saúde em dois municípios do Nordeste do Brasil. Cienc Saude Colet. 2005; 10 Supl:141-55.

8. Cortes SMV. Construindo a possibilidade da participação dos usuários: Conselhos e Conferências no Sistema Único de Saúde. Sociologias. 2002; 4(7):18-49.

9. Monteiro MG, Fleury S. Democracia deliberativa nas gestões municipais de saúde: um olhar sobre a importância dos conselhos municipais de saúde nas gestões. Saude Debate. 2006; 30(73/74):219-33.

10. Stotz EM. Trajetória, limites e desafios do controle social do SUS. Saude Debate. 2006; 30(73/74):145-8.

11. Van Stralen CJ, Lima AMD, Fonseca SD, Saraiva LES, Van Stralen TBS, Belisário SA. Conselhos de Saúde: efetividade do controle social em municípios de Goiás e Mato Grosso do Sul. Saude Debate. 2006; 11(3):621-32.

12. Moreira MR, Escorel S, Fernandes FMB, Delgado MM, Sucena LFM, Oliveira AN. A democratização nos Conselhos de Saúde. Saude Debate. 2006; 30(73/74):205-18.

13. Pinheiro MC, Westphal MF, Akerman M. Eqüidade em saúde nos relatórios das Conferências nacionais de saúde pós-Constituição Federal brasileira de 1988. Cad Saude Publica. 2005; 21(2):449-58.

14. Müller Neto JS, Schrader FAT, Pereira MJVS, Nascimento IF, Tavares LB, Motta AP. Conferências de saúde e formulação de políticas em 16 municípios de Mato Grosso, 20032005. Saude Debate. 2006; 30(73/74):248-74.

15. Habermas J. Teoria da la acción comunicativa. Madri: Taurus Humanidades; 1987.

16. Freitag B, Rouanet SP. Habermas. 3a ed. São Paulo: Ática; 1993.

17. Yin R. Case study research: design and methods. 2a ed. Califórnia: Sage Publications; 1994.

18. Bardin L. Análise de conteúdo. Lisboa: Edições 70; 1979.

19. Testa M. Saber en salud. Buenos Aires: Lugar Editorial; 1997. 
Miranda AS, Moreira AEMM, Cavalcanti CGCS, Bezerra FM, Oliveira JC, Rezende R. Discursos prácticos sobre hechos, procesos decisorios y consecuencias de las Conferencias Municipales de Salud en Brasil. Interface (Botucatu). 2016; 20(58):559-71.

¿Qué significados pueden destacarse en los discursos de participantes de las Conferencias Municipales de Salud? Se analizaron conferencias realizadas en el Noreste de Brasil durante el año 2007. Este fue un estudio de múltiples casos, de fundamentación teórica hermenéutica y dialéctica, basado en técnicas de análisis documental, entrevistas y grupos focales. En las conferencias se destacaron la posibilidad de expresión y movilización de algunos grupos de intereses por demandas específicas, escenarios de interlocución competitiva y búsqueda de mediaciones políticas orientadas para la obtención de cierta eficacia simbólica eventual. Sobre las consecuencias de las decisiones deliberadas, se destacaron ciertos discursos sobre la negligencia de los gobiernos municipales en la incorporación de estas demandas en sus agendas políticas, así como en el despliegue de estrategias institucionales correspondientes. También se reveló la ausencia de monitoreo por parte de los respectivos Consejos Municipales de Salud.

Palabras clave: Conferencias de Salud. Consejos de Salud. Sistema Brasileño de Salud. Participación ciudadana. 
